\title{
Correspondence
}

\section{"Flaws" in the Review of Chinese Stories from Taiwan}

In response to the review of Chinese Stories from Taiwan, 1960-1970, edited by Joseph S. M. Lau and myself, by Lorraine Dong and Marlon Kau Hom, which appeared in the Journal of Asian Studies for August I977, I would like to offer these comments:

It is true that we did not notify readers that the ending of Yü Li-hua's "In Liu Village" had been changed from the original. But since the translation is by the author and Professor C. T. Hsia, is it even worth bringing up the highly unlikely possibility that the change was made without the author's approval? Yü Li-hua collaborated with Professor Hsia on the new ending to "In Liu Village." Subsequently, she translated it into Chinese (with a few phrases slightly expanded) for the definitive version of Liu-chia chuang-sbang, which appeared in Miss Yü's short story collection Pai-chü cbi (The white pony) (Taipei: Hsien-jen-chang ch'u-pan-she, 1969).

The English title "Flaw" of Wang Wen-hsing's story was chosen by the author himself.

The introductory note to Lin Huai-min's "Cicada" on page 242 clearly states that the translation is from the version of the story appearing in the book of the same name, published in Taipei by Ta-ti ch'u-pan-she in I973, and that with the author's permission some sections have been deleted. Why take us to task for differing from the original version?

Finally, the Foreword by Professor Hsia is not all that brief. It runs eighteen pages, and it seems to me unjust to dismiss it as "sketchy."

Timothy A. Ross

Arkansas State University

\section{Professor Schafer Would Say ...}

I am not sure whether I should find obscure gratification or nervous alarm at being introduced as a major figure, in the likeness of a skeletal memento mori, into the central portion of Mr. Chaves's reply (JAS, XXXVII, November 1977, pp. I 86-88) to Mr. Lynn's review (XXXVI, May I977, pp. 55 I-54). But I can hardly avoid a public statement about the acceptance, for printing in a reputable journal, of misrepresentations of my opinions, used as part of a rejoinder to another scholar's review. I am even more nettled by the publication of Mr. Chaves's translation of a couplet, foisted off as my own ("Professor Schafer would say: . .."). I do not think that Mr. Chaves has any idea what I would say. 